J. ODERFELD (Warszawa) i S.ZUBRZYCKI (Wrocław)

\title{
O SPRAWDZANIU WODOMIERZY
}

\section{Sformulowanie zagadnienia}

Narzedzia miernicze, wytwarzane masowo w ustalonych warunkach produkcji, jak np. wodomierze, maja błędy systematyczne i blędy przypadkowe. Każde narzędzie podlega badaniu, którego celem jest sprawdzenie, czy błąd systematyczny nie przekracza wielkości z góry ustalonej. Ze względu na błędy przypadkowe pozytywny wynik badania nie jest jeszcze dowodem, że warunek co do dokładności jest na pewno spełniony. Podobnie, wynik negatywny nie jest dowodem, że warunek co do dokładności jest na pewno niespelniony. Można natomiast przywiązacé do tego rodzaju orzeczeń pewne zaufanie co do ich poprawności. Nadanie im określonej miary liczbowej jest możliwe przy użyciu metod probabilistycznych.

W sposób naturalny nasuwają się dwa pytania. Pierwsze z nich stawia odbiorca, który pragnie wiedzieć, jakie jest prawdopodobieństwo, że narzędzie uznane za dobre jest naprawdę dobre. Drugie pytanie stawia wytwórca, który pragnie wiedzieć, jakie jest prawdopodobieństwo, ze narzędzie wykonane przez niego w warunkach produkcji uregulowanej będzie uznane za dobre. Przedmiotem niniejszego artykułu jest udzielenie odpowiedzi na drugie pytanie. Bezpośrednią pobudka do napisania niniejszego artykulu stala się praca Obalskiego ${ }^{1}$ odpowiadając a na pierwsze $"$ postawionych pytań.

Z cytowanej pracy wynikają następujące założenia i reguły postępowania. Błędy systematyczne $x$ wodomierzy maja rozklad normalny o średniej $a$ i odchyleniu średnim $\sigma_{0}$, co zapiszemy krótko w postacj "mają rozkład $N\left(a, \sigma_{0}\right)$ ". Wodomierz, którego błąd syste-

1) J. Obalski, O pewnosici wyników sprawdzania narzẹdzi miermiczych. Zastosowania Matematrki 1.2 (1953). str. 105.124. 
matyczny jest $x$, ma błąd przypadkowy o rozkładzie $N\left(x, \sigma_{1}\right)$. Parametry $a, \sigma_{0}$ i $\sigma_{1}$ pewnego typu wodomierza można uważać $\mathrm{w}$ warunkach produkcji uregulowanej za stałe $\mathrm{i}$ znane $z$ doświadczenia. Każdy wodomierz podlega sprawdzeniu, przy którym rejestruje się jego błąd rzeczywisty $m$, zdefiniowany przez wzór

$$
m=\frac{\text { wskaranie wodomierza - wskazanie przyrządu wzorcowego }}{\text { wskazanie przyrządu wzorcowego }}
$$

Przepis ${ }^{2}$ ) Głównego Urzędu Miar ustala największy dozwolony błąd systematyczny $q$, największą liczbę pomiarów, wynoszącą dwa, i tok postępowania dający się ując $w$ tabliczkę.

\begin{tabular}{|c|c|c|}
\hline $\begin{array}{l}\text { Orzekanie } \\
\text { na podstawie }\end{array}$ & Wynik pomiarów & Decyzja \\
\hline $\begin{array}{l}\text { pierwsyego } \\
\text { pomiaru }\left(m_{1}\right)\end{array}$ & $\begin{array}{c}\left|m_{1}\right| \leqslant 0,9 q \\
\left|m_{1}\right| \geqslant 1,1 q \\
0,9 q<\left|m_{1}\right|<1,1 q\end{array}$ & $\begin{array}{l}\text { Uznać wodomierz za dobry } \\
\text { Uznać wodomierz za niedobry } \\
\text { Wykonać drugi pomiar, któ- } \\
\text { regowynik oznacza sie przez } m_{2} \text {. } \\
\text { Obliczyé } \bar{m}=0,5\left(m_{1}+m_{\Omega}\right)\end{array}$ \\
\hline $\begin{array}{l}\text { średniej } \\
\text { bu pomiarón }(m)\end{array}$ & $\begin{array}{l}|\bar{m}| \leqslant q \\
|\bar{m}|>q\end{array}$ & $\begin{array}{l}\text { Uznac wodomierz za dobry } \\
\text { Uznac wodomierz za niedobry }\end{array}$ \\
\hline
\end{tabular}

Przedmiotem niniejszego artykułu jest wyznaczenie prawdopodobieństwa, ż wodomierze systematycznie sprawdzane wedlug zacytowanego przepisu będa uznawane za dobre. Znajomość tego prawdopodobieństwa pozwala wytwórcy na zorientowanie sie w potrzebnej dokładności jego metod produkcyjnych i na ocene ryzyka związanego $z$ dyskwalifikacją wodomierzy przez kontrolera Urzędu Miar, a więc na ocenę korzyści, jakie może przynieść zmiana parametrów $a, \sigma_{0}, \sigma_{1}$ przez ulepszenie metor prorlukeji.

Za podstawe rozwigzania przyjmujemy:

a) zacytowane przepisy.

b) założenia Obalskiego co do rozkładu błędów oraz stalości i znajomości parametrów $a, \sigma_{0}$ i $\sigma_{1}$.

Rozwizzzanie odnosi się oczywiście poza wodomierzami do wszelkich przyparków analogicznych.

2) Instrukcja legalizacyjna dla przepływomierzy wodnych zamkniętych (wodomierzy). Wykonywanie legalizacji. 11. III.49. Przepiky obowiqzujące $w$ miernictwie, poz. $2,722 / 1,3$. 


\section{Rozwiązanie ogólne}

2.1. Oznaczenia.

\begin{tabular}{|c|c|c|}
\hline Oznaczenie & Określenie & Rodzaj \\
\hline$x$ & Bład systematyczny & \\
\hline$m_{1}$ & Wynik pierwszego pomiaru & Zmienne losowe \\
\hline$m_{2}$ & Wynik drugiego poiniaru & \\
\hline$m$ & $0,5\left(m_{1}+m_{2}\right)$ & \\
\hline$q$ & $\begin{array}{l}\text { Największy dozwolony bład syste. } \\
\text { matyczny }\end{array}$ & \\
\hline$a, \sigma_{0}$ & $\begin{array}{l}\text { Srednia i odchylenie średnie w nor. } \\
\text { malnym rozkładzie } x\end{array}$ & $\begin{array}{l}\text { Niezależue } \\
\text { parametry }\end{array}$ \\
\hline$\sigma_{1}$ & $\begin{array}{l}\text { Odchylenie średnie w normalnym } \\
\text { rozkładzie błedu przypadkowego } \\
m \text {. wokół sredniej } x \\
\sigma_{0}\end{array}$ & techniczne \\
\hline$!$ & & Bezw y miarowe, \\
\hline$h$ & $\frac{1}{q}$ & $\begin{array}{l}\text { niezaleźne para- } \\
\text { metry techniczne }\end{array}$ \\
\hline $7:$ & $\bar{q}$ & \\
\hline$" \prime$ & $\frac{\sqrt{\sigma_{0}^{2}}+\sigma_{1}^{2}}{q}=\sqrt{g^{2}+h}$ & \\
\hline$p$ & 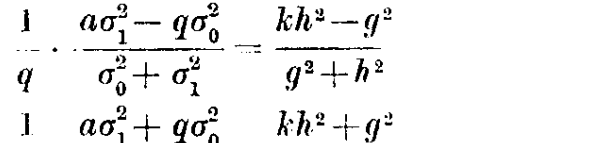 & $\begin{array}{l}\text { Bezwy miarowe } \\
\text { wspólczynniki } \\
\text { pomocuicze }\end{array}$ \\
\hline$r$ & $q \cdot \frac{1}{\sigma_{0}^{2}+\sigma_{1}^{2}}=\frac{q^{2}+h^{2}}{g^{2}}$ & potolocurez \\
\hline$\therefore$ & $\underset{q}{1} \sqrt{\frac{\sigma_{0}^{2} \sigma_{1}^{2}}{\sigma_{0}^{2}+\sigma_{1}^{2}}+\sigma_{1}^{2}=h \sqrt{\frac{2 g^{2}+h^{2}}{g^{2}+h^{2}}}}$ & \\
\hline$\mu_{1}$ & $\bar{q}$ & $\begin{array}{l}\text { Znormalizowane } \\
\text { znienne losowe }\end{array}$ \\
\hline$\mu_{2}$ & $q$ & \\
\hline$P_{1}$ & $\begin{array}{l}\text { Prawdopodobienstwo uznania wo. } \\
\text { domierza za dobry po I pomiarze }\end{array}$ & \\
\hline$P_{2}$ & $\begin{array}{l}\text { Prawdopodobieństwo uzuania wo- } \\
\text { domierza za dobry po II po- } \\
\text { miarze }\end{array}$ & $\begin{array}{l}\text { Prawdopodobien- } \\
\text { stwa }\end{array}$ \\
\hline$l^{\prime}$ & $P_{1}+P_{2}$ & \\
\hline$p(y)$ & $\frac{1}{\sqrt{2 \pi}} e^{-\ddot{y} / 2}$ & Funkeja Gaussal \\
\hline$\theta(z)$ & $\int_{0} \varphi(y) d y$ & Funkcja Laplace'a \\
\hline
\end{tabular}


2.2. Charakterystyka. Reguła postępowania podana w rozdziale 1 stanowi pewien plan badania. Przez jego charakterystyke będziemy rozumieli zależność między prawdopodobieństwem $P$ uznania wodomierza za dobry, a wadliwościa $w$ partii wodomierzy przy danych parametrach rozkładów błędów. Wadliwość partii jest to stosunek liczby wodomierzy o błędzie systematycznym $|x|>q$ do liczby wszystkich wodomierzy w partii.

Ponieważ $x$ ma z założenia rozkład normalny $\left(a, \sigma_{0}\right)$, więc

gdzie

$$
x=1-\theta\left(\begin{array}{c}
q-a \\
\sigma_{0}
\end{array}\right)-\theta\left(\begin{array}{c}
q+a \\
\sigma_{0}
\end{array}\right),
$$

$$
\theta(z)=\frac{1}{\sqrt{2 \pi}} \int_{0}^{z} e^{-y^{2 / 2}} d y
$$

oznacza funkcje Laplace'a.

Wprowadzając wielkości bezwymiarowe

otrzymujemy

$$
\begin{aligned}
& g=\frac{\sigma_{0}}{q}, \\
& k=\frac{a}{q},
\end{aligned}
$$

$$
w=1-\theta\left(\frac{1-k}{g}\right)-\theta\left(\frac{1+k}{g}\right) .
$$

Błąd $m_{1}$ zaobserwowany w pierwszym pomiarze można uwazać za sume zmiennej losowej $x$, która $z$ założenia ma rozkład normalny $\left(a, \sigma_{0}\right)$, oraz zmiennej losowej $m_{1}-x$, która $z$ założenia ma rozkład normalny $\left(0, \sigma_{1}\right)$. Wobec niezależności obu zmiennych losowych $m_{1}$ ma rozklad normalny $\left(a, \sqrt{\sigma_{0}^{2}+\sigma_{1}^{2}}\right)$. Prawdopodobieństwo $P_{1}$ uznania wodomierza za dobry po pierwszym pomiarze jest takie samo, jak prawdopodobieństwo, że $\left|m_{1}\right| \leqslant 0,9 q$. A więc

$$
P_{1}=\theta\left(\frac{0,9 q-a}{\sqrt{\sigma_{0}^{2}+\sigma_{1}^{2}}}\right)+\theta\left(\frac{0,9 q+a_{1}}{V^{\prime}-\sigma_{0}^{2}+\sigma_{1}^{2}}\right) \text {. }
$$

Wprowadzając oznaczenia

$$
h=\frac{\sigma}{q}
$$


oraz

znajdujemy

$$
n=\frac{\sqrt{\sigma_{0}^{2}+\sigma_{1}^{2}}}{q}=\sqrt{g^{2}+h^{2}}
$$

$$
P_{1}=\theta\left(\frac{0,9-k}{n}\right)+\theta\left(\frac{0,9+k}{n}\right)
$$

Aby doszło do drugiego pomiaru, trzeba, żeby zaszła podwójna nierówność

$$
0,9 q<\left|m_{1}\right|<1,1 q .
$$

Aby konsekwencja drugiego pomiaru było uznanie wodomierza za dobry, trzeba, żeby zaszła nierówność

$$
|\bar{m}| \leqslant q
$$

gdzit

$$
\bar{m}=0,5\left(m_{1}+m_{2}\right) \text {. }
$$

Prawdopodobieństwo uznania wodomierza za dobry po drugim pomiarze jest

$$
P_{2}=\iint_{(n)} f\left(m_{1}, m_{2}\right) d m_{1} d m_{2}
$$

gdzie $f\left(m_{1}, m_{2}\right)$ oznacza gęstość lącznego rozkładu $m_{1}$ i $m_{2}$, $G$ zaś obszar całkowania określony przez (8), (9) i (10). W dalszym ciagu będziemy oznaczali ogólnie przez $p(t)$ gęstość prawdopodobieństwa zmiennej losowej $t$, a przez $p_{u}(t)$ gęstość prawdopodobieństwa warunkowego zmiennej losowej $t w$ zależności od wartości zmiennej losowej $u$. Gęstość $f\left(m_{1}, m_{2}\right)$ można przedstawié w postaci

$$
f\left(m_{1}, m_{2}\right)=p\left(m_{1}\right) p_{m_{1}}\left(m_{2}\right) .
$$
kowego

Zmienna losowa $m$, ma z załozenia gęstość rozkladu bezwarun-

$$
p\left(m_{1}\right)=\frac{1}{\sqrt{2 \pi} \sqrt{\sigma_{0}^{2}+\sigma_{1}^{2}}} \exp \left\{-\frac{\left(m_{1}-a\right)^{2}}{2\left(\sigma_{0}^{2}+\sigma_{1}^{2}\right)}\right\} .
$$

Gęstość $p_{m_{1}}\left(m_{2}\right)$ obliczymy uwzględniając, że oba pomiary wykonywa się na tym samym wodomierzu o błędzie systematycznym $x$. Przed tym obliczymy gęstośc $\tilde{p}_{m_{1}}(x)$ rozkladu blędów systenatycz- 
nych wodomierzy, kt6re dały $m_{1}$ jako wynik pierwszego pomiaru. Zachodzi tożsamość

$$
p\left(m_{1}\right) p_{m_{1}}(x)=\tilde{p}(x) p_{x}\left(m_{1}\right)
$$

gdzie

$$
\tilde{p}(x)=\frac{1}{\sqrt{2 \pi} \sigma_{0}} \exp \left\{-\frac{(x-a)^{2}}{2 \sigma_{0}^{2}}\right\}
$$

oraz

$$
p_{x}\left(m_{1}\right)=\frac{1}{\sqrt{2 \pi} \sigma_{1}} \exp \left\{-\frac{\left(m_{1}-x\right)^{2}}{2 \sigma_{1}^{2}}\right\} .
$$

Wstawiając (13), (15) i (16) do (14) znajdujemy

$$
\tilde{p}_{m_{1}}(x)=\frac{1}{\sqrt{2 \pi} \frac{\sigma_{0} \sigma_{1}}{\sqrt{\sigma_{0}^{2}+\sigma_{1}^{2}}}} \exp \left\{-\frac{\left(x-\frac{m_{1} \sigma_{0}^{2}+a \sigma_{1}^{2}}{\sigma_{0}^{2}+\sigma_{1}^{2}}\right)^{2}}{2 \frac{\sigma_{0}^{2} \sigma_{1}^{2}}{\sigma_{0}^{2}+\sigma_{1}^{2}}}\right\} .
$$

Zmienna losowa $m_{2}-x$ ma z założenia rozkład $N\left(0, \sigma_{1}\right)$. Ponieważ zaś zmienna losowa $m_{2}$ jest sumą niezależnych zmiennych losowych $x$ i $m_{2}-x$, więc warunkowy rozklad drugiego pomiaru jest

$$
p_{m_{1}}\left(m_{2}\right)=\frac{1}{\sqrt{2 \pi} \sqrt{\frac{\sigma_{0}^{2} \sigma_{1}^{2}}{\sigma_{0}^{2}+\sigma_{1}^{2}}+\sigma_{1}^{2}}} \exp \left\{-\frac{\left(m_{2}-\frac{m_{1} \sigma_{0}^{2}+a \sigma_{1}^{2}}{\sigma_{0}^{2}+\sigma_{1}^{2}}\right)^{2}}{2\left(\frac{\sigma_{0}^{2} \sigma_{1}^{2}}{\sigma_{0}^{2}+\sigma_{1}^{2}}+\sigma_{1}^{2}\right)}\right\} .
$$

Ostatecznie

$$
P_{2}=\iint_{(G)} p\left(m_{1}\right) p_{m_{1}}\left(m_{2}\right) d m_{1} d m_{2},
$$

gdzie funkcje podcałkową określają równania (13) i (18), obszar zaś całkowania jest określony przez (8), (9) i (10).

Oszacowanie podwójnej całki występującej po prawej stronie wzoru (19) jest łatwe. Możemy bowiem, ze względu na wasski przedział zmienności $\left|m_{1}\right|$, napisać $w$ przybliżeniu 


$$
P_{2}=p\left(m_{1}=-q\right) \cdot \int_{-1,1 q}^{-0,9 q} d m_{1} \int_{-q}^{3 q} p_{m_{1}}\left(m_{2} ; m_{1}=-q\right) d m_{2}+
$$

czyli

$$
+p\left(m_{1}=q\right) \cdot \int_{0,9 q}^{1,1 q} d m_{1} \int_{-3 q}^{q} p_{m_{1}}\left(m_{2} ; m_{1}=q\right) d m_{1}
$$

$$
P_{2}=0,2 q \cdot p\left(m_{1}=-q\right) \cdot \int_{-q}^{3 q} p_{m_{1}}\left(m_{2} ; m_{1}=-q\right) d m_{2}+
$$

$$
+0,2 q \cdot p\left(m_{1}=q\right) \cdot \int_{-3 q}^{q} p_{m_{1}}\left(m_{2} ; m_{1}=q\right) d m_{2}
$$

Wprowadzamy oznaczenia

$$
\begin{aligned}
p & =\frac{-q \sigma_{0}^{2}+a \sigma_{1}^{2}}{\sigma_{0}^{2}+\sigma_{1}^{2}} \cdot \frac{1}{q}=\frac{-g^{2}+k h^{2}}{g^{2}+h^{2}}, \\
r & =\frac{q \sigma_{0}^{2}+a \sigma_{1}^{2}}{\sigma_{0}^{2}+\sigma_{1}^{2}} \cdot \frac{1}{q}=\frac{g^{2}+k h^{2}}{g^{2}+h^{2}}, \\
s & =\sqrt{\frac{\sigma_{0}^{2} \sigma_{1}^{2}}{\sigma_{0}^{2}+\sigma_{1}^{2}}+\sigma_{1}^{2} \cdot \frac{1}{q}=h \sqrt{\frac{2 g^{2}+h^{2}}{g^{2}+h^{2}}},} \\
\mu_{1} & =\frac{m_{1}}{q}, \\
\mu_{2} & =\frac{m_{2}}{q} .
\end{aligned}
$$

Wobec wzorów (13) i (18), i przy uwzględnieniu oznaczeń wprowadzonych przez wzory (3), (6), (22), (23), (24), (25) i (26), napiszemy wzór (21) w postaci

$$
P_{2}=\frac{0,2}{n} \cdot \frac{1}{\sqrt{2 \pi}} e^{-\frac{1}{2}\left(\frac{-1-k}{n}\right)^{2}} \int_{\mu_{2}=-1}^{\mu_{2}=3} \frac{1}{\sqrt{2 \pi}} e^{-\frac{1}{2}\left(\frac{\mu_{2}-p}{s}\right)^{2}} d\left(\frac{\mu_{2}-p}{s}\right)+
$$

$$
+\frac{0,2}{n} \cdot \frac{1}{\sqrt{2 \pi}} e^{-\frac{1}{2}\left(\frac{1-k}{n}\right)^{2}} \int_{\mu_{2}=-3}^{\mu_{2}=1} \frac{1}{\sqrt{2 \pi}} e^{-\frac{1}{2}\left(\frac{\mu_{2}-r}{s}\right)} d\left(\frac{\mu_{2}-r}{8}\right) .
$$

Oznaczmy funkcje Gaussa przez $\varphi$. Będzie 


$$
\varphi(y)=\frac{1}{\sqrt{2 \pi}} e^{-y^{2} / 2} .
$$

Wobec (1) i (28) wyrazenie (27) przechodzi w

$$
\begin{aligned}
P_{2}=\frac{0,2}{n} \varphi\left(\frac{1+k}{n}\right) & \left.\mid \theta\left(\begin{array}{c}
3-p \\
s
\end{array}\right)+\theta\left(\frac{1+p}{s}\right)\right]+ \\
\cdot & 0,2 \frac{1-k}{n} \varphi\left(\frac{1-k}{n}\right)\left[\theta\left(\frac{3+v}{n}\right)+\theta\left(\frac{1-r}{n}\right) \mid .\right.
\end{aligned}
$$

Wróćmy teraz do glównego toku rozumowania. Całkowite prawdopodobieństwo uznanis wodomierzar zal dobry jest

$$
P=P_{1}+P_{2} \text {. }
$$

Wzory (4), (29) i (30) stanowią rozwiazanie zagadnienia. ofak latwo zauwazyć, $P$ jest funkeja trzech bezwymiarowych niezalezinych parametrów technicznych $g, h \mathrm{i} k$, a warliwośc $w$ jest funkeją $g$ i $k$. Rugując jeden $z$ tych trzech parametrów otrzymamy zależność $P$ od $w$ w postaci równania $z$ dwoma parametrami. Jest to poszukiwana charakterystyka.

\section{Przyklady zastosowunia}

Zakladając rózne wartości $k$, można dla każdej z nich stablicowac $p=f(w ; g, h)$.

Obliezenie wykonane dla $k=0$ prowalzi do tablicy 1 i wykresow na rysunku 1. '/upethie podobne krzywe otryymuje się, gdy $k \neq 0$.

Tablica I

Kależności $g(w)$ oraz $P(w ; h)$ dla $k=0$.

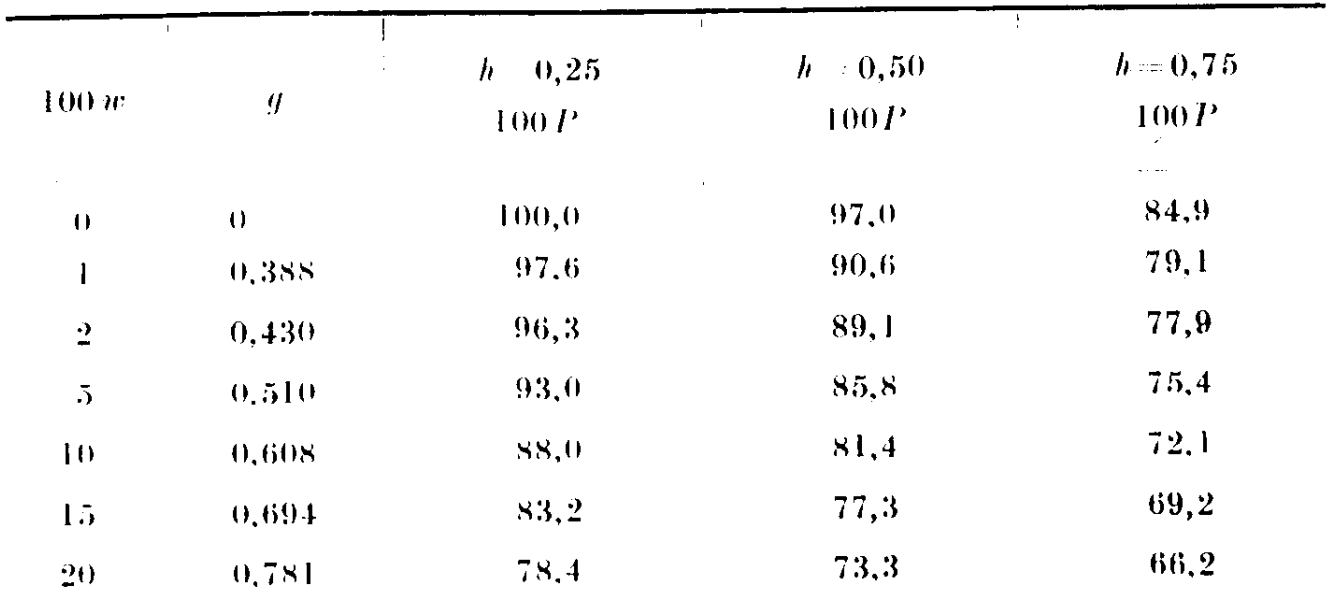




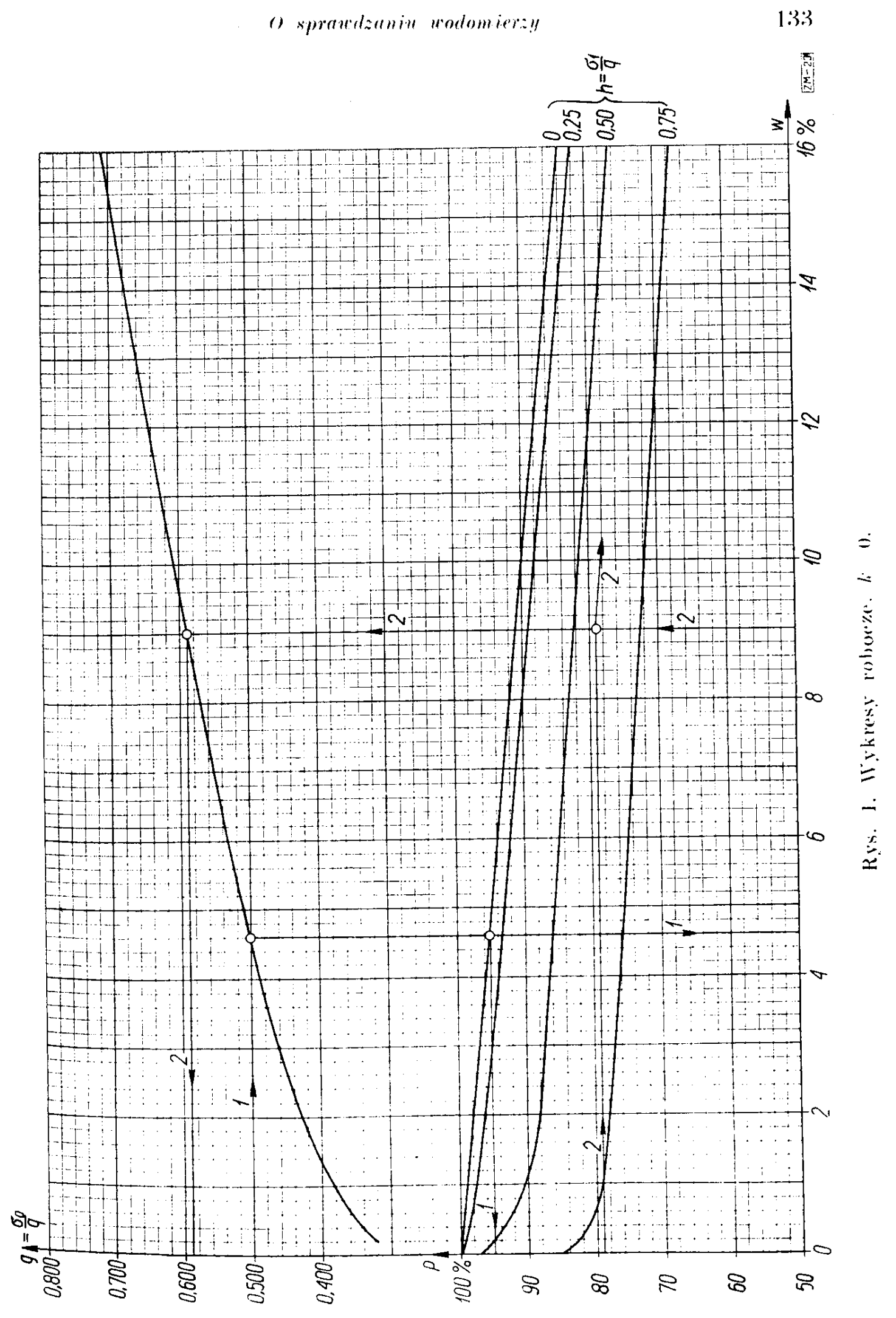


Stosowanie wykresów do zagadnien szezególowych pokażemy na kilku przykładach. Wszystkie liczby $w$ nich występujące sa fikcyjne i służą tylko do zilustrowania metody.

Przykład 1. Z przepisów wynika, że $q=1,2 \%$. Dlugotrwałe badanie pokazało, że $a=0, \sigma_{0}=0,6 \%, \sigma_{1}=0,3 \%$. Jaka jest frakcja wodomierzy niedobrych i jaka będzie frakcja wodomierzy uznanych za niedobre?

Obliczamy

$$
k=\frac{a}{q}=0,
$$

wobec czego stosuje się rysunek 1 ,

$$
\begin{aligned}
& g=\frac{\sigma_{0}}{q}=0,5, \\
& h=\frac{\sigma_{1}}{q}=0,25 .
\end{aligned}
$$

Wychodząc z $g=0,5$ i z $h=0,25$ prowadzimy na rysunku 1 linie ze strzałkami, oznaczone cyfra 1 i znajdujemy, że niedobrych wodomierzy jest $w=4,3 \%$ i że $1-P=7 \%$ wodomierzy będzie uznanych za niedobre.

Przykład 2. Z przepisów wynika, że $q=1,5 \%$. Z doświadczenia wiadomo, że $a=0$ i że przeciętnio za niedobre uznajo się $21 \%$ wodomierzy; na podstawie kart kontrolnych ustalono, że przeciętna wadliwość jest $9 \%$. Ile wynosi odchylenie średnie $\sigma_{0}$ błędu systematycznego $x$, a ile odchylenie średnie $\sigma_{1}$ błędu przypadkowego $m_{1}-x$ ?

Wychodząc na rysunku 1 z $w=9 \%$ i $P=100 \%-21 \%=79 \%$, prowadzimy linie ze strzałkami oznaczone cyfra 2 i znajdujemy, że $g=0,58$ oraz $h=0,6$.

Obliczamy

$$
\begin{aligned}
& \sigma_{0}=q g=1,5 \% \cdot 0,58=0,9 \% ; \\
& \sigma_{1}=q h=1,5 \% \cdot 0,6=0,9 \% .
\end{aligned}
$$

\section{Wnioski ogólne}

Jednym z aspektów postẹpowania odbiorczego prowadzonego na towarach sztukowych jest jego zdolnośé oddzielania przedmiotów dobrych od niedobrych. W przypadku wodomierzy zdolność 
ta nie jest zupeha, nawet gdy sprawdzamy każdą sztukę, a to przez błędy przypadkowe, sprawiające, że nie każdy wodomierz uznany za dobry jest na pewno dobry i nie każdy wodomierz uznany za zły jest na pewno zły. Badanie tej zdolności było przedmiotem zacytowanej pracy Obalskiego, któremu chodziło o to, by przez odpowiednie postępowanie odbiorcze zapewnić duże prawdopodobieństwo, że wodomierz uznany za dobry jest dobry.

Również z naszej tablicy 1 widać, że postępowanie oparte na przepisie GUM może odróżniać wodomierze dobre od złych bardzo niedokładnie. Mianowicie w miare jak rośnie parametr $h$, charakteryzujący przypadkowy błąd wodomierza, maleje prawdopodobieństwo $P$ uznania wodomierza za dobry. I tak dla $h=0,75$ przy $w=1 \%$ jest $P=79,1 \%$; a więc w produkcji zawierającej $1 \%$ sztuk wadliwych za złe uznałoby się w tych warunkach przeszło $20 \%$ wodomierzy. Jeszcze jaskrawiej występuje to przy $w=0$ i $h=0,75$, kiedy $P=84,9 \%$; mimo więc, że wszystkie wodomierze sa dobre, dyskwalifikujemy $\mathrm{z}$ nich $15 \%$. Podobny efekt występuje przy wszystkich wadliwościach.

Drugim aspektem jest czułość, $z$ jaka przepis reaguje na zmiane wadliwości. Mała czułość mogłaby spowodować słabe zainteresowanie producenta wadliwością jego produktu.

Z bezpośredniej analizy tablicy 1 widać, że niezależnie od parametrów technicznych prawdopodobieństwo uznania wodomierza za dobry maleje $w$ przybliżeniu liniowo wraz $z$ wadliwością, tym wolniej, im większe sa blędy przypadkowe. Tak na przykład bardzo poważne zwiększenie wadliwości z $2 \%$ na $10 \%$ zmniejsza prawdopodobieństwo uznania wodomierza za dobry

$$
\begin{aligned}
& \text { przy } h=0,25 \text { z } 96,3 \% \text { na } 88,0 \% \text {, czyli o } 8,3 \% \text {, } \\
& \text { przy } h=0,50 \text { z } 89,1 \% \text { na } 81,4 \% \text {, czyli } \circ 7,7 \% \text {, } \\
& \text { przy } h=0,75 \text { z } 77,9 \% \text { na } 72,1 \% \text {, czyli } 05,8 \% .
\end{aligned}
$$

W tych warunkach jest wytwórcy prawie wszystko jedno, jaką wadliwość utrzymuje. A więc przepis GUM, którego to jest konsekwencją, nie stanowi dla wytwórcy dostatecznej zachęty do podwyższenia jakości, ani ostrzeżenia przed jej znacznym obniżeniem. Czułość postępowania opartego na przepisie GUM jest bardzo mala.

Dlatego warto rozważyć, czy lepszych wyników nie da kontrola wyrywkowa. Polegałaby ona na sprawdzaniu tylko niektórych 
wodomierzy z. produkcji bieżącej, ale za to każdego więcej razy, niż obecnie. $W$ razie pomyślnego wyniku całą partie uznawałoby się za dobra, w razie niepomyślnego wyniku wszystkie wodomierze $z$ partii poddawałoby się badaniu indywidualnemu. Przez odpowiedni dobór planu badania można by stworzyé warunki, w których producent byłby żywo zainteresowany w obniżaniu wadliwości (np. przez zmniejszanie $\sigma_{0}$ lub a, lub obu parametrów jednocześnie) i w unikaniu jej podwyższania. W ten sposób kontrola $z$ rejestracyjnej stałaby się aktywna. Możliwe, że cel ten można by osiagnąc przy całkowitej liczbie pomiarów na partie niewiększej niż obecnie i przy frakcji złych wodomierzy przesaczających sie przez kontrolę niewyższej, niż przy obecnym systemie.

Instytut Matematyczny Polskiej Akademii Nauk

(Praca wplynela dnia 2\%. 1\%. 1952 r.)

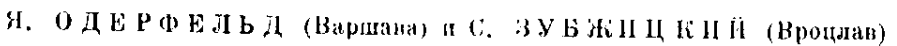

\section{() IIPOBEPKE BO,ДOMEPOB PEЗ $О \mathrm{ML}$}

Измерительные приборы, например нодомеры, нзготовляемые массовым образом в определенных условиях производства, имеют погрешности спстематпчекіе $r$, п случайные. Каждыи прибор проверяется, сохранено . ног положительное пнсло. В статье разрешен следующий вонрос: пропіводитель желает знать зависнмость между вероятиостью $P$ того, что ирибор будет призиан годным при проверке, и процентом $w$ брака партии $(w$... отношение чнсла приборон, не соответстьу юших требонаниям, коп̆ьему партии). Правила приема следующие:

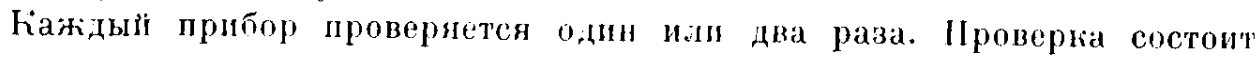
н том, что пзиеряется погрешность прибора путем сравииания его с ойраз цом.

ІІусть $m_{1}$ "l $m_{2}$ соответсквущие результаты первого и второго измерения. ІІрибор признается годным, если $\left|m_{1}\right| \leqslant 0,9 q$ и негодным, если $\left|m_{1}\right| \geqslant 1,1 q$. Eciп $0,9 q<\left|m_{1}\right|<1,1 q$, то проводится второе пзмерение, после

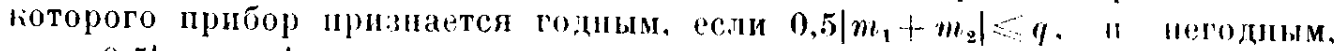
если $0,5\left|m_{1}+m_{2}\right|>q$.

ІІринимаем, что $x$ по нсем пзделиям имеет нормальное pachpeделение $\left(a, \sigma_{0}\right)$, а результат $m$ изиерения погениости прибора с систематической погрениостю $x$ пмет пормалиое распределение $\left(x, \sigma_{1}\right)$. ПТараметри, $a, \sigma_{n}, \sigma_{1}$ навестны пз опьта. 
Әффентивное решение дано в виде графиков, которые определяют характеристику правила приема в форме $f\left(w, P ; a, \sigma_{0}, \sigma_{1}, q\right)=0$.

Дано несколько примеров пользования графиками.

Общий анализ приведенного правила проверки водомеров приводит li критическим заюююениям о сеиственности правила.

J. ODERFELD (Warszawa) and S. ZU B RZY CKI (Wrocław)

\section{ON TESTING FLOWMETERS}

\section{$\therefore$ UMMAR Y}

Measuring instruments, mass produced in stabilized production conditions, e.g. flowmeters, have systematical errors $x$ and random errors. Each instrument is tested with the object of ascertaining whether it fulfils the condition of accuracy $|x| \leqslant q$, where $q$ is a positive number fixed arbitrarily beforehand. The paper deals with the problem of the producer, who wants to know the relation between the probability $P$ of the instrument produced passing the test as good and the fraction defective $w$ of the lot, $i$. e. the ratio of the number of instruments which fall short of the requirements of the test to the size of the lot. The rules of testing are as follows:

We test each instrument once or twice measuring its error by comparing it with the standard. Let $m_{1}$ and $m_{2}$ be the results of the first and the second measurement of $x$ respectively.

If $\left|m_{1}\right| \leqslant 0,9 q$, the instruments is considered good. If $\left|m_{1}\right| \geqslant 1,1 q \ldots$ it is considered defective.

If $0,9 q<\left|m_{1}\right|<1,1 q$, a second measurement is taken: in that case the in. strument is considered good if $0,5\left|m_{1}+m_{2}\right| \leqslant q$; it is considered defective if $0,5\left|m_{1}+m_{2}\right|>q$.

We assume that $r$, in the whole of production, has the normal distribution $\left(a, \sigma_{0}\right)$, and the result $m$ of the error measurement of an instrument with the systematic error $x$ has the normal distribution $\left(x, \sigma_{1}\right)$. The parameters $a, \sigma_{0}, \sigma_{1}$ are known from experiment.

Diagrams which give the characteristic curve of the rules of testing in the form $f\left(w, P ; a, \sigma_{0}, \sigma_{1}, q\right)=0$ are an effective solution.

Several examples of the use of those diagrams have been given.

Moreover, the authors have made a general analysis of described rules of testing flowmeters and reached ritical conclusions as regards the effectiveness of those rules. 